\title{
Preservação da madeira: práticas brasileiras do passado e oportunidades de pesquisa para o futuro
}

\author{
Wood preservation: brazilian practices from the past \\ and research opportunities for the future
}

\section{Carlos Dion de Melo Teles}

Engenheiro de materiais e doutor em Arquitetura (USP-EESC)

E-mail edionteles@yahoo.com.br

Osny Pellegrino Ferreira

Engenheiro civil e doutor em Engenharia Civil (USP-EESC)

E-mail:osnypefe@sc.usp.br

\section{ResUMo}

É feita uma revisão histórica do emprego de preservantes de madeira, da última década do século XIX a 1961, servindo de referência para restauradores e arqueologia arquitetônica no campo, bem como na identificação de oportunidades de pesquisa para comprovação e resgate de técnicas do passado. São citados o alcatrão vegetal, creosoto, sulfato de cobre, cloreto de zinco, bicloreto de mercúrio, pinturas à óleo, carbonização superficial, fluoreto de sódio, arseniato de cobre cromato, hidróxido de potássio ou sódio, cal, secagem adequada, lixiviação da seiva e abate em época do ano adequada.

Palavras-chave: Preservação de madeira; Patrimônio histórico; Materiais para construção

\begin{abstract}
This article presents the use of wood preservers from late XIX century to 1961, serving as a reference for heritage restorers and architectural archaeology, as well as for identifying research opportunities on testing and rescuing ancient techniques. The consolidated data shows that tar, vegetable tar, copper sulphate, zinc chlorate, mercury bi-chlorate, oils based painting, superficial carbonization, sodium fluorate, copper chrome arsenate, potassium hydroxide, sodium hydroxide, wood seasoning procedures, sap lixiviation and correct logging season.
\end{abstract}

Keywords: Wood preservation; Cultural heritage; Construction materials 
1 - HERÓDOTO, $\mathrm{H}$. As histórias de Heródoto. [484-424 aC]) apud RICHARDSON, B.A. Wood preservation. Landcaster: The Construction, 1978. preocupação com a degradação das madeiras é, provavelmente,
tão antiga quanto seu uso. Embora seja difícil localizar sua primeira
iniciativa, Richardson (1978) apresenta uma interessante retrospectiva de sua prática no mundo ocidental. Ele atribui à Bíblia a primeira referência a uma técnica de preservação, onde Noé é instruído por Deus a passar piche por dentro e por fora da embarcação que suplantaria o dilúvio.

O grego Heródoto [1] (484-424 AC, apud RICHARDSON, 1978) foi um antecessor dos historiadores, tendo registrado muitos fatos de sua época, entre os quais a extração de óleos, alcatrão e resinas, que poderiam ter sido usadas na preservação. Há na obra de Heródoto descrições da operação de mumificação, que foram empregadas com sucesso na preservação de madeiras, séculos depois, por Boulton. O egiptologista Robert Brier narra alguns tipos de preservação de objetos de madeira encontrados em escavações do Egito antigo. Ainda segundo Richardson, há também evidências de preservação de madeira pelos chineses, no século 1 A.C., por imersão em água do mar. Também os romanos teriam usado cobre metálico como preservante, evidência encontrada em madeiras de antigas minas. $\mathrm{O}$ naturalista romano Pliny (23-79 A.C.) teria descrito mais de 48 essências úteis na preservação da madeira, entre as quais o bagaço de azeitonas, óleos de cedro, valeriana, larch e juniper. Já antes dos romanos era dito que Alexandre O Grande (356-323 AC) ordenara cobrir madeiras de pontes com óleo de oliva para protegê-las.

As Grandes Navegações trouxeram uma nova necessidade em preservação de madeiras. Na época de Vasco da Gama (1469-1524), segundo Richardson (1978), os portugueses carbonizavam a parte externa das embarcações para protegê-las de degradações por xilófagos marinhos. A degradação era tão grave que as embarcações da Companhia das Índias Ocidentais raramente fazia mais do que quatro viagens antes de serem inutilizados por degradação fúngica. Esta baixa duração se agravou na Inglaterra, quando no século XVIII a industrialização competia com as embarcações pelo uso das florestas remanescentes. No século XIX as companhias ferroviárias passam a competir também pela madeira para seu combustível, e enfrentam um grave problema: a madeira é tida como 
o melhor material para dormentes dos trilhos, mas degradam muito rapidamente. Assim há um grande impulso na busca por preservativos industriais. Em 1810 a Enciclopédia Britânica trazia um verbete sobre preservação de madeira, com listas de preservativos originalmente publicados em 1770, por Sir John Pringle. Em 1842 cinco processos de preservação estavam estabelecidos: cloreto de mercúrio, sulfato de cobre, cloreto de zinco, sulfato e sulfito ferroso, além de creosoto. O Quadro 1 traz uma breve cronologia adaptada de Richardson (1978).

Quadro 1: Cronologia de citação ou patente de preservativos (baseado em RICHARDSON, 1978)

\begin{tabular}{|c|c|c|c|}
\hline Ano & Preservativo & Cientista & País \\
\hline 1705 & Cloreto de mercúrio & Citado por Homberg & França \\
\hline 1767 & Sulfato de cobre & De Boissieu e Bordenave & França \\
\hline 1815 & Cloreto de Zinco & Thomas Wade & Inglaterra \\
\hline 1838 & Creosoto & John Bethell & Inglaterra \\
\hline 1864 & & $\begin{array}{l}\text { Louis Pasteur anuncia que } \\
\text { micro-organismos são os } \\
\text { causadores do apodrecimento }\end{array}$ & França \\
\hline
\end{tabular}

\section{A PRESERVAÇão DE MADEIRA NO BRASIL: DE 1880 A 1961}

O que um profissional de restauro deve esperar encontrar como preservativos em madeiras do seu objeto de estudo? Pode-se dizer a idade de uma peça de madeira pelo seu preservativo? No caso de substituição de peças deterioradas por peças idênticas às originais, que preservativo utilizar? Que incompatibilidades podem-se prever entre reforços e preservativos? Estas são algumas perguntas que levaram à pesquisa bibliográfica em publicações ligadas à construção civil e marcenaria.

Apesar de abranger um período histórico mais restrito que o desejável, o presente trabalho deverá ser ampliado oportunamente, à medida que mais referências sejam encontradas e que comprovações de campo possam ser feitas.

Século XIX. Huguenin é um autor francês que adaptou um aide- 
mémoire de engenharia alemã, da editora Hütte, para a realidade francesa. O exemplar consultado (HUGUENIN, 188?), da quarta edição, foi encontrado em Porto Alegre (RS), e data do final do século XIX (a referência mais recente no texto é de 1883). O autor, que tem como referência as condições na Europa, cita como 100 anos a duração média do cedro, durando 50 anos em situações de umidade, 300 a 400 em situações secas e indefinidamente quando submerso. Já a faia teria duração média de 75 anos e as coníferas 85 anos em média e 20 anos em situações de umidade.

Em 1905, outra publicação européia encontrada no Brasil é a obra de Figueiredo, sobre construções rurais. Nela há uma preocupação com sistemas aplicáveis nas zonas rurais, embora cite alguns mais complexos. Preocupado com os prejuízos causados pelas brocas nas madeiras recém abatidas, o anilhamento das árvores, procedendo da seguinte forma: no início da primavera retira-se o anel de súber, que irá impedir a passagem da seiva, um ao pé da árvore e outro por baixo das "pernádas" (ramificações de primeira ordem). Quando a árvore definhar e emurchecer, entre agosto e janeiro no calendário europeu, é derrubada. Desta forma provoca-se a absorção do amido disponível na seiva, diminuindo a propensão ao ataque de insetos à árvore.

Como medidas de conservação, são citadas a secagem além de injeções e indutos. Os produtos usados nas injeções são os seguintes:

- Sulfato de cobre: 1 a 5\% em água;

- Sulfato de zinco: 1 a 3 \% em água;

- Sublimado corrosivo (outro nome do bicloreto e mercúrio, também chamado antigamente de protocloreto de mercúrio): 0,2 a 0,5\% em água;

- Creosoto;

- Formol: de 0,4 a 0,6\%.

Apontada a dificuldade de se usar autoclaves na realidade rural, Figueiredo (1905) propõe a imersão por cerca de oito dias na solução escolhida.

Como indutos, usados para cobrir a superfície da madeira, são indicados o pez, o alcatrão, o asfalto e o coaltar ou piche ou "borra do gás”. É interessante lembrar que embora o asfalto e o coaltar sejam hoje 
tipicamente produtos de petróleo, antes da difusão do petróleo o alcatrão e o piche eram originários do pez de coníferas. Já a borra do gás é provavelmente um subproduto da produção de gás de iluminação utilizada na época, a partir de carvão mineral. Figueiredo também recomenda a carbonização superficial as partes da madeira ficarem enterradas.

As pinturas são outra forma preventiva. "A tinta, de um óleo secativo (óleo de linhaça) com uma substáncia sólida, pulverizada constitui um revestimento preservativo contra inséctos e micróbios” (p. 79).

Apesar de não serem aplicáveis na zona rural, Figueiredo cita ainda dois processos, sendo um de secagem rápida e outro por impregnação:

$1^{\circ}$ expondo as madeiras em estufas a 40 e $50^{\circ} \mathrm{C}$, 'para solidificar a seiva'. Mas a evaporação rápida é inevitável e d'aí resulta empenárem. $2^{\circ}$ mergulhando-as 'em água corrente límpida, durante 3 a quatro meses.' $3^{\circ}$ metendo-as em agua quente, a $30^{\circ} \mathrm{C}$ por espaço de 3 a 4 dias. Estes dois últimos tornam a madeira 'muito leve' mas roubam-lhe 'a dureza e a resistência', e em operação complementar expõe-se a uma ventilação moderáda. (p. 78)

O processo do Sr. Nodon-Bertoneau, denominado senilisação, é preconisado no estrangeiro: as madeiras são submetidas a uma corrente elétrica energica, por meio da qual (...) se extrai a seiva, injectando-se imediatamente uma substancia antiséptica ou incombustível. A solução usada é de boro-resináto neutro de sóda, que se conserva a 30 ou $40^{\circ} \mathrm{C}$ (...). A corrente atravessa toda a espessura das peças de madeira interpóstas a laminas de chumbo. A operação faz-se no prazo d'algumas horas (...) (La Nature, 7-10 - 1889). (p. 78)

Outro trabalho, um tratado de construções civis, é publicado por Barberot em 1920. Nesta época a França exercia grande influência no Brasil, motivo pelo qual se inclui seu livro nesta revisão, cujo exemplar foi encontrado no Rio de Janeiro. São sugeridos: 
- Secagem por dois anos para uso em carpintarias e quatro anos para uso em marcenarias;

- Abate da árvore em época adequada (na Europa, de 15 de novembro a 15 de dezembro);

- Flotação de três a quatro meses em água doce, para madeiras duras (como o carvalho);

- Secagem artificial à temperaturas de 30 a $40^{\circ} \mathrm{C}$ para angiospermas e de 80 a $95^{\circ} \mathrm{C}$ para coníferas;

- Secagem em estufa com fumaça, em particular para madeiras que contenham o ácido pirolenhoso (carvalho, faia, nogueira, olmo etc.) A albumina da seiva é expulsa, dando lugar ao "elemento conservador obtido naturalmente" (p.900);

- Carbonização superficial formando uma camada que contém creosoto;

- Injeções de cloreto de zinco, sulfato de cobre, protocloreto de mercúrio ou creosoto (indican do detalhes da operação);

Sobre o abate em época adequada, podemos apoiar esta recomendação no estudo atual (LIMA et al., 2002), que mostra claramente a variação de açúcares na seiva e em diferentes partes de seringueiras (Hevea brasiliensis Müll. Arg.) entre o inverno e o verão. Embora a madeira da seringueira não seja comumente utilizada, a variação dos açúcares pode servir como indício para outras espécies, sendo esses atrativos aos insetos.

Para conservação de madeiras já trabalhadas Barberot sugere ainda:

- A aplicação de pinturas a óleo;

- Zarcão (na época, o óxido de chumbo $\mathrm{Pb}_{3} \mathrm{O}_{4}$ );

- "Goudron" ou "alcatrão destilado de vegetais, ossos ou hulha" (dicionário Petit Robert);

- "Coaltar" ou alcatrão de hulha;

- Esterilização dos "fermentos de destruição" pela secagem ou pela injeção de antisépticos.

Entre as páginas 53 e 55, são recomendados os seguintes processos preservantes: 
- Pinturas a óleo;

- Revestimento à quente com uma fina camada de alcatrão de poix - emulsão aquosa do resíduo de destilação da terebintina, obtida de árvores resinosas coníferas, como o pinho (ALTIF, 2006). Espécie de pez.

- Terebintina: contra os "vermes", pincelar uma camada de terebintina;

- Lixívia e sal: contra os "vermes", pincelar uma camada de lixívia cáustica (normalmente hidróxido de potássio) e sal de cozinha " $26 \mathrm{p}$. pour 3p" - provavelmente proporção em peso.

- Tabaco e alcatrão: pincelar com um induto composto de galhos de tabaco em alcatrão.

"Em casos onde a duração da madeira é de uma importância capital, podemos, após tê-las secado, as impregnar com os antisépticos seguintes” (p.54, tradução livre):

- Sulfato de cobre: uma parte para 50 partes de água, injetado à uma pressão de oito a dez atmosferas;

- Cloreto de zinco: uma parte para 24 de água. Mergulhar a madeira em vapor durante uma a duas horas, no vácuo de uma a duas horas e meia, e na solução durante uma a duas horas, a oito atmosferas;

- Protocloreto de mercúrio: uma parte para 50, submergir a madeira de oito a nove dias na solução;

- Creosoto: submeter ao vácuo durante uma hora e em seguida na solução por duas horas, a oito atmosferas.

Em outra publicação, Pinheiro ([191?], p.259-271) aborda a madeira como material de construção. Cita como métodos "profiláticos":

- Descascar a árvore depois de abatê-la; lavar por quatro meses em água; proceder a secagem. Sugere também a lavagem à vapor, mais rápida, porém aponta uma perda de resistência da madeira;

- Abate das árvores em época adequada. "São 
contraditórias as opiniões acerca da época do ano mais favorável para o corte das árvores (...). Uma grande maioria indica, porém, o outono ou o começo do inverno como época mais propícia (...).” (p. 319)

Para proteção da madeira em obra Pinheiro [191?] propõe:

- A aplicação de indutos (alcatrão, tintas e vernizes);

-A injeção de substâncias "antisépticas" (creosoto, sulfato de cobre, cloreto de zinco ou bicloreto de mercúrio);

-A "vulcanização" da madeira, por autoclavagem em ar quente pressurizado por oito horas. Ressalva todavia que "seus resultados têm sido por vezes contraditórios";

- A carbonização superficial, "método mais antigo usado em peças enterradas satisfatoriamente desde a Grécia antiga". Acrescenta que "este método aplicado a navios não teve grande sucesso na marinha da Inglaterra."

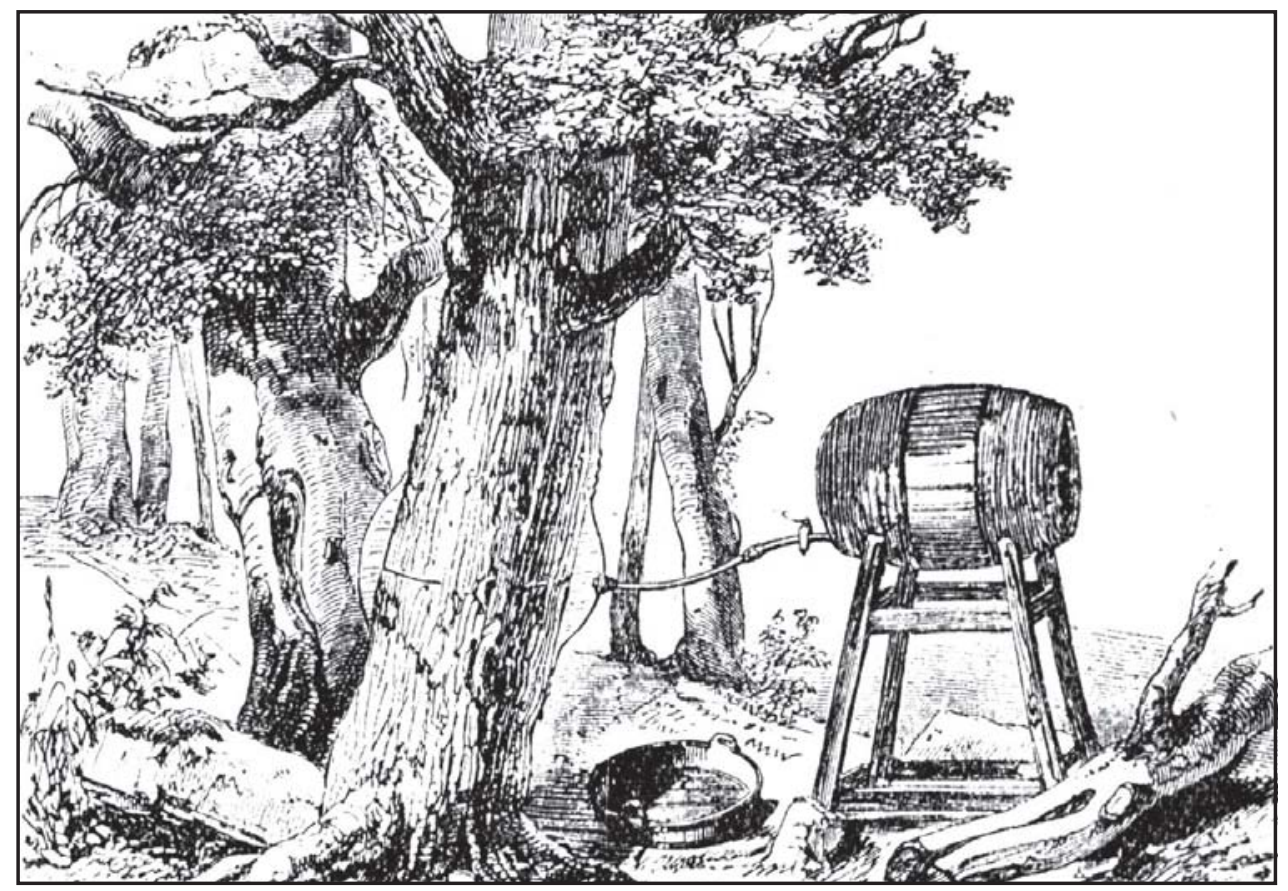

Figura 1 - Método Boucherie original, onde se aproveita a evapo-transpiração da árvore para injetar-Ihe uma solução de sulfato de cobre, antes do abate. (PINHEIRO, [191?]) 
Pinheiro [191?] chega a descrever as formas correntes de aplicação, incluindo usando o mecanismo de evapo-transpiração das plantas (Figura 1), por gravidade e sob pressão (Figura 2). Também discorre sobre a diferença entre o creosoto proveniente da destilação da madeira (que contém "parafina e ácido fênico") e o proveniente da destilação do carvão de mineral (que contém "naftalina e ácido fênico"). Alerta também para a grande toxidade do bicloreto de mercúrio.
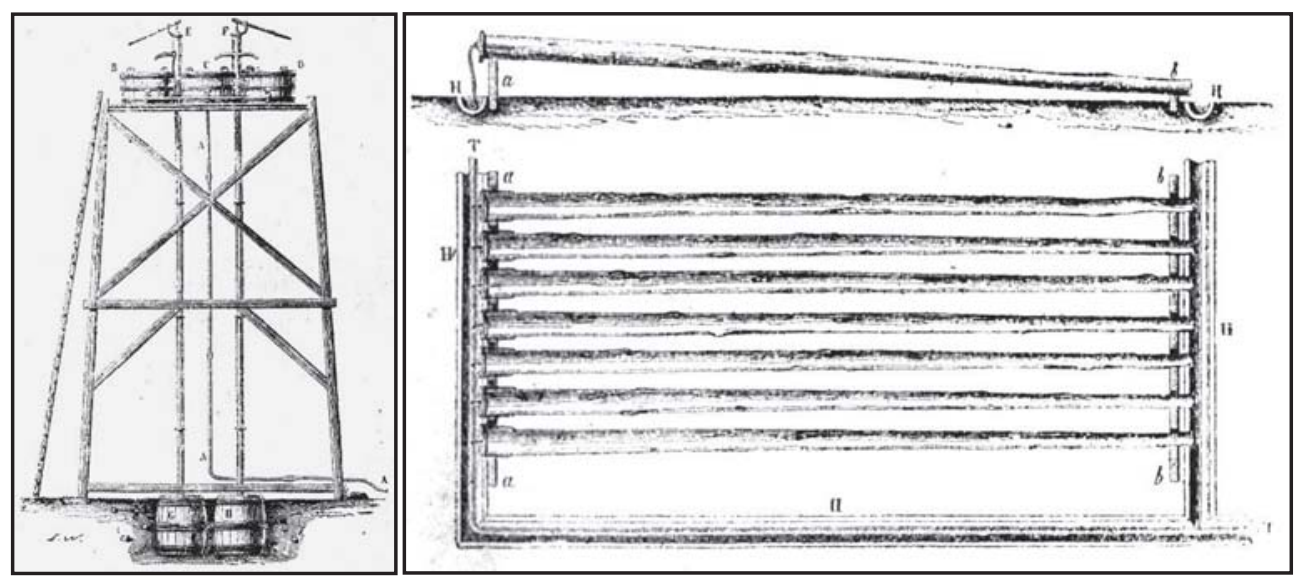

Figura 2 - Sistema de tratamento de postes segundo a evolução do método Boucherie. À esquerda a disposição dos postes em vista lateral e superior, onde um tubo é ligado à base do poste por meio de um flange estanque. À Direita, torre de cerca de dez metros para proporcionar pressão à solução de sulfato de cobre. (PINHEIRO, [191?])

Em 1928, é publicada a primeira edição de Materiales de Construcción, do engenheiro M. Foerster, da qual consultamos a terceira edição, de 1942. Cita, como fonte de degradação, os fungos. Sugere, antes de tudo, que se use madeira de boa qualidade e que seja mantida em local seco. Como meios de preservação superficial, cita (p.166):

-Envernizamento com óleo de linhaça;

- Pinturas a óleo;

- Alcatrões de madeira ou hulha, com resina (não precisa que resina);

- Alcatrão de madeira misturado com cal apagada;

-Carbolíneo, "antinonnina” (provavelmente sulfeto de antimônio) e "isol", um "isolante líquido elástico, resistente a ácidos e bases” (provavelmente um nome comercial); 
2 - Segundo Berst (1942) a caparrosa azul é o sulfato de cobre. Supõe-se daí que a caparrosa verde possa ser 0 sulfato ferroso, que possui esta cor. Segundo o Diccionario della lengua española, da Real Academia Española, seria corante de tinturaria, sulfato ferroso.
Como protetivos de impregnação, aponta (p. 166 a 168):

- Óleo de creosoto ("óleo de alcatrão com 6 a 10\% de ácido fênico");

- Cloreto de zinco, sob pressão;

- Sulfato de cobre, por evapo-transpiração da planta (método Boucherie);

- Cloreto de mercúrio, ressalvada sua toxidade;

- Caparrosa verde [2] e sulfato de alumina, seguido de cloreto de cálcio e leite de cal ("procedimento Hasselmann”).

Cita ainda mais três métodos:

- A cabonização superficial, todavia pondo em dúvida sua eficácia. Sugere para melhorá-la revestir as superfícies com argila, alcatrão, chapas de aço, etc.

- Lixiviação (lavagem) da seiva em água corrente;

- Lavagem da seiva por vapor.

Outra referência é o Manual del Ingeniero Constructor, organizada por F. Schleicher em 1948 e encontrada no Rio de Janeiro. É uma obra de grande abrangência nas áreas de engenharia civil, e por isto breve no tópico que nos interessa aqui. Nas paginas 430 e 431, Otto Graf traz recomendações quanto à proteção da madeira contra "putrefação e insetos", estando em grande parte ligadas à evitar a umidade na madeira. $\mathrm{O}$ abate de árvores durante o outono ou inverno é justificado para evitar o ataque de fungos.

Como protetivos, são recomendados tratamentos com:

- Carbolíneo (destilado leve do alcatrão de hulha);

-Xilamón (nome comercial de um produto, cuja fórmula pode ter mudado com o tempo);

- Pinturas impermeáveis sobre madeira seca, e bem conservada (pintura sem gretamento).

Sugere a "a impregnação em forma e momento adequado", sem detalhes, mas referindo-se algumas fontes para maiores referências.

Marcellini [195?], em seu manual de marcenaria, propõe que as 
madeiras expostas ao ar sejam protegidas com vernizes, mastiques ("resina vegetal extraída de certas anacardiáceas, especialmente da aroeira”) [3] ou alcatrão. Já para madeiras enterradas sugere a carbonização superficial ou injeções de sulfato de cobre, cloreto de zinco, pirolenhito de ferro ou creosoto. Se o foco for eliminar insetos, adiciona o bicloreto de mercúrio à lista.

Já em 1961, a ampla compilação de Argentière e outros, o Novíssimo Formulário Industrial, traz na página 291 informações chegando a detalhar as concentrações de produtos e forma de aplicação. São os preservativos nele apontados:

- Bicromato de Cobre, que "reage rapidamente e se transforma em cromato básico de cobre, pouco solúvel";

- Bicloreto de mercúrio, aplicado por imersão;

- Óleo de alcatrão, contra o emboloramento;

- Soluções em água de sais de cobre zinco e mercúrio;

- Fluoreto de sódio;

- Fluossilitados de zinco e magnésio, apontados como lixiviáveis;

- Cloreto de zinco, ressalvando que, ao estabilizar, gera ácido clorídrico, que pode atacar conectores de ferro;

- Bicromato de potássio, aplicado com fluoretos alcalinos, arseniato sódico e nitrofenóis;

Focando em construções rurais, o prof. Carneiro publicou a $6^{\mathrm{a}}$ edição de sua obra em 1961. A parte que trata de preservação de madeiras conta com contribuições do dr. Paulo Ferreira de Souza e dr. Felipe Cabral de Vasconcelos. Divide os tratamentos em superficiais e de impregnação. Entre os tratamentos contamos:

- Carbonização superficial: indicada para madeira enterrada no solo;

- Pintura com creosoto ou piche: usados aquecidos ou diluídos para melhor penetração;

- Pintura à base de óleo, em especial com zarcão; 
- Sulfato de cobre, $1 \%$ em água (evitar contato com ferro);

- Solução de cal, de 5 a 8\% em água;

- Bicloreto de mercúrio, 0,6\% em água;

- Fluoreto de sódio;

- Cloreto de zinco;

- Creosoto ou óleo creosotado;

- Processo Wolman: impregnação industrial com CCA (Arseniato de cobre cromato)

- Cal (20kg), Sulfato de Cobre (1kg), Arseniato de Cálcio (250g), água (100 litros quando pincelado, 150 litros se empregada pulverização).

\section{Resultados e Discussão}

Mesmo sem cobrir todo o universo de publicações do período, serão feitas análises considerando representativa a população apresentada.

Podemos considerar o número de citações como indício de comprovação de sua eficácia, condicionada a outros fatores como disponibilidade do produto, publicidade, entre outros. Não será uma prova de que os preservantes pouco citados não seriam eficazes, mas somente que os mais citados seriam mais comprovados. Podemos ver no Quadro 2 os preservantes citados mais de uma vez entre as obras consultadas.

Quadro 2: Preservantes citados mais de uma vez nas obras estudadas

\begin{tabular}{|l|l|}
\hline № Citações & Preservativo \\
8 & Bicloreto de mercúrio \\
8 & Creosoto \\
7 & Sulfato de cobre \\
5 & Cloreto de zinco \\
5 & Alcatrão superficial ou derivados \\
5 & Carbonização superficial \\
4 & Tintas, pinturas à óleo \\
3 & Lavagem em água corrente \\
2 & Abate da árvore em época adequada \\
2 & Fluoreto de sódio \\
2 & Lavagem à vapor \\
2 & Secagem adequada \\
\hline
\end{tabular}


Podemos também considerar a longevidade do uso de um produto como fator de comprovação de sua eficácia, também condicionada com outros fatores já citados. Neste caso, os produtos recomendados por mais anos, da sua primeira citação à última, indicaria sua eficácia e disponibilidade ao uso. Todavia quando um produto cai em desuso não implica necessariamente em ineficácia. Existem outros condicionantes que provocam uma mudança de preferências, como a disponibilidade de outro produto substituto de mais fácil aplicação ou disponibilidade; fatores comerciais como royalties; fatores técnicos como a popularização dos conectores metálicos, passíveis de corrosão por alguns preservantes; fatores econômicos, implicando na exploração ao longo do ano todo ou na venda sem secagem da madeira; entre outros. No Quadro 3 vemos a cronologia das citações dos preservantes entre as obras consultadas.

Ainda é interessante observar os preservantes citados apenas uma vez. Seu desconhecimento nas demais obras não implica em ineficácia,

Quadro 3: cronologia de citação dos preservantes

\begin{tabular}{|c|c|c|c|c|c|c|c|c|}
\hline Preservante & [188?] & 1905 & [191?] & 1920 & 1942 & 1948 & $195 ?$ & 1961 \\
\hline Bicloreto de mercúrio & |||||||||||| & |||||||||||| & |||||||||| $\mid$ & |||||||||||| & $|\||||||||||$ & & |||||||||| $\mid$ & |||||||||| \\
\hline Creosoto & |||||||||||| & |||||||||||| & |||||||||||| & |||||||||||| & |||||||||||| & & |||||||||||| & |||||||||| \\
\hline Sulfato de cobre & |||||||||||| & |||||||||||| & |||||||||||| & |||||||||||| & |||||||||||| & & |||||||||||| & |||||||||| \\
\hline Cloreto de zinco & |||||||||| $\mid$ & & |||||||||| $\mid$ & $|\||||||||||$ & $\|||||||||||$ & & |||||||||| $\mid$ & $\||||||||| \mid$ \\
\hline Alcatrão superficial ou derivados & |||||||||||| & |||||||||||| & |||||||||||| & & & |||||||||||| & |||||||||||| & |||||||||| \\
\hline Carbonização superficial & & |||||||||||| & |||||||||||| & |||||||||||| & $|\||||||||||$ & & & |||||||||| \\
\hline Tintas, pinturas à óleo & |||||||||||| & |||||||||||| & & |||||||||||| & & |||||||||||| & |||||||||||| & |||||||||| \\
\hline Lavagem em água corrente & & |||||||||||| & |||||||||||| & |||||||||||| & $|\|||||||||| \mid$ & & & \\
\hline Abate da árvore em época adequada & & $|\||||||||||$ & |||||||||||| & $|\||||||||||$ & & & & \\
\hline Fluoreto de sódio & & & & & & & & $\||||||||| \mid$ \\
\hline Lavagem à vapor & & & |||||||||||| & & $|\|||||||||| \mid$ & & & \\
\hline Secagem adequada & & |||||||||||| $\mid$ & & |||||||||||| $\mid$ & & & & \\
\hline Zarcão $\left(\mathrm{Pb}_{3} \mathrm{O}_{4}\right)$ & & & & |||||||||||| & & & & |||||||||| $\mid$ \\
\hline
\end{tabular}


que entre outros fatores, podem ser métodos regionais, sem comprovação da comunidade científica, sem distribuição comercial eficaz ou com preços proibitivos. Vemos no Quadro 4 os preservantes menos citados entre as obras consultadas.

Quadro 4: Preservantes menos citados

\begin{tabular}{|l|l|}
\hline Preservativo & Autores \\
\hline Terebintina & Huguenin (188?) \\
\hline Lixívia e Cloreto de Sódio & Huguenin (188?) \\
\hline Tabaco e alcatrão & Huguenin (188?) \\
Sulfato de zinco & Figueiredo (1905) \\
Formol & Figueiredo (1905) \\
Asfalto, piche, borra do gaz & Figueiredo (1905) \\
Processo Nodon-Bertoneau & Figueiredo (1905) \\
Vulcanização da madeira & Pinheiro (191?) \\
Secagem com fumaça & Barberot (1920) \\
Óleo de linhaça & Foerster (1942) \\
Alcatrão de madeira misturado com cal apagada & Foerster (1942) \\
Carbolíneo, antinonnina e isol & Foerster (1942) \\
Caparrosa verde, sulfato de alumina, cloreto de cálcio e leite de cal & Foerster (1942) \\
CCA (Arseniato de cobre cromato) & Carneiro (1961) \\
\hline
\end{tabular}

\section{ConClusÕes}

Quando o leitor analisar os dados apresentados, deve estar atento à mudança da nomenclatura com o tempo. Alcatrão e creosoto tendem a ter origem predominantemente vegetal nas referências mais antigas, porém sua produção passou a ser predominante da hulha ou petróleo mais recentemente. A evolução do processo de destilação e a valorização de outros produtos da hulha e petróleo fizeram com que fossem subtraídos vários compostos do alcatrão e o creosoto, empobrecendo-os.

Mesmo o alcatrão vegetal, que tem entre seus elementos ativos o ácido pirolenhoso, pode ter diferentes efeitos dependendo de sua origem. Uma origem tradicional é o pinho e outras coníferas resinosas. Costa et al. (2003) mostram em seu estudo que a eficácia do ácido 
pirolenhoso varia conforme a espécie que lhe dá origem. Segundo Paes et al. (2002) o creosoto vegetal, quando originado de árvores folhosas, possui inclusive um caráter ácido, que pode ser danoso às ferragens empregadas na madeira tratada.

As tintas superficiais tradicionais empregavam o óleo de linhaça, de notado efeito preservante, muitas vezes tendo como pó secante o litargírio $(\mathrm{PbO})$, seguramente pouco atrativo a insetos. Muitas vezes ainda era adicionado o zarcão $\left(\mathrm{Pb}_{3} \mathrm{O}_{4}\right)$, também um composto de chumbo. Assim, esta tinta tende a ter um efeito preservante mais eficaz do que as atuais tintas industrializadas.

O próprio óleo de linhaça hoje vendido nas lojas de tintas não é mais o óleo de linhaça que se empregava: apresenta-se misturado ao óleo mineral e outros componentes.

Quanto à evolução dos preservantes no período estudado, pode-se perceber que as técnicas de secagem, abate em época adequada e lavagem em água corrente deixam de ser citadas a partir de um período. CCA e o fluoreto de sódio só são citados em 1961, enquanto outros aparecem durante todo o período.

Do ponto de vista de arqueologia arquitetônica, vemos os principais preservantes foram empregados durante longos períodos, dificultando sua datação. Outros, como o CCA e o Fluoreto de Sódio somente são encontrados mais recentemente. Eventualmente o presente estudo poderá ser ampliado, buscando datar quando caíram em desuso o bicloreto de mercúrio, o sulfato de cobre e o cloreto de zinco, servindo assim de referência para datação. Já outros métodos sequer deixam marcas veementes, como a lavagem em água corrente, o abate em época adequada e a secagem.

No caso do patrimônio rural, o uso de recursos disponíveis na própria fazenda versus insumos industrializados poderá ser ligado aos períodos históricos de maior autonomia versus períodos de maior facilidade de comércio. É sempre interessante consultar a biblioteca da fazenda sobre publicações técnicas que possam ter influenciado as práticas locais. Fontes de informação orais também podem contribuir com dados relevantes.

Do ponto de vista de oportunidades para pesquisa, é preciso acrescentar aos dados apresentados mais informações sobre a toxidade, o im- 
4 - Agradecemos às professoras Maria Ângela Bortolucci e Akemi Ino pelo apoio na formalização deste artigo. pacto ambiental e os custos atualizados dos métodos. Do ponto de vista ambiental podem representar boas oportunidades:

- A pintura a óleo de linhaça, substituindo o pó secante por outro menos tóxico;

- Óleo de linhaça puro;

- Carbonização superficial;

- O alcatrão, creosoto ou carbolíneo de origem vegetal com comprovada eficácia, com tabaco ou não;

- Terebintina;

- A lixiviação de seiva com água;

- O abate em época adequada;

- Lixívia com cloreto de sódio;

- Soluções de cal, com ou sem outros sais, precavendo contra a provável oxidação dos conectores;

- Soluções de sulfato de cobre ou cloreto de zinco, em locais onde não houver lixiviação e tomadas as precauções quanto à oxidação dos conectores. [4]

\section{REFERENCIAS BIBLIOGRÁFICAS}

ARGENTIÈRE, R. et al. Novíssimo Formulário Industrial. São Paulo: LEP, 1961.

ATILF - Laboratoire D'analyse Et Traitment De La Langue Française Lexilogos: dictionaire français. Disponível em: $<$ http://www.lexilogos.com/ francais_langue_dictionnaires.htm>. Acesso em: 17 de junho de 2006.

BARBEROT, E. Constructions Civiles. Paris: CH Béranger, 1920.

BERST, J. Recetario Industrial y Domestico: 17.000 Recetas y Métodos Aplicables a Todas Las Industrias, Artes y Ofícios y Al Alcance De Todos. Buenos Aires: Montesó,1942.

BORDAlLO, T. Biblioteca de Instrução Profissional: Materiais de Construção. Rio de Janeiro: Francisco Alves, [191?].

BRIER, R. History of Ancient Egypt. Chantilly: The Teaching, [199?]. 24 CDs.

CARNEIRO, O. Construções Rurais. 6.ed. São Paulo: Carioca, 1961.

COSTA, A. et al. "Estudo comparativo entre produtos químicos 
preservantes e licores pirolenhosos na inibição de fungos emboloradores". In: Brasil Florestal, Brasília, n.75, jan. 2003.

FIGUEREDO, A. Construções Rurais. Habitações Estábulos, Oficinas e Arrecadações Agrícolas. Porto: Chardron, 1905.

FOERSTER, M. Materiales de Construcción. 3.ed. Buenos Aires: Labor, 1942. (Manuales Técnicos Labor, 34). 